\title{
Chilli grinding as an opening to the study of occupational lung disease
}

When in 1962 I started work at Chest Clinic Kandy, I occasionally used to buy chilli powder for domestic use at a chilli grinding mill at Katukelle in Kandy. The freshly ground powder at the mill was supposed to be more potent than and preferable to the old stuff sold in retail shops. Whenever I entered the premises I was assailed with bouts of coughing and sneezing, sometimes violently when the dust was disturbed, but surprisingly the workers carried on regardless. The question why I was affected while the workers themselves were symptom-free puzzled me at the time.

When the situation recurred on several occasions, I thought of investigating the problem, but I was faced with a difficulty. The management of the mill would not take kindly to an outsider like me questioning the workers, and thereby possibly causing labour unrest. My immediate problem would be solved if I could find some official reason for workers to be examined at Chest Clinic. At this stage, I came to know that the chilli grinding mills, as well as all other industrial undertakings within the Kandy Municipal Council, had to be licensed annually with the Council through its Medical Officer of Health (MOH). The Chief MOH, who was personally known to me, was Dr K C D Perera, who incidentally, was an acknowledged expert on ancient coins of Sri Lanka. When I told him my problem, he at once agreed to assist me. He immediately instructed one of his Public Health Inspectors to get the workers at all the chilli grinding mills in Kandy examined by me at the Chest Clinic before their annual licences could be renewed.

Consequently, 19 workers from 6 mills in Kandy were examined by me. Nearly all of them developed symptoms, namely cough, sneezing, watering of nose and burning sensation of the body at the beginning of their employment, but became free of them with the passage of time. after varying periods. In some, the symptoms lasted for only a week, while in one worker they went on for 6 months. This finding explained my personal experience on visiting the mill, for being a newcomer it was not surprising that I developed symptoms on entering the premises.

At that time I did not realise the importance of the finding. It was only later that I discovered that workers in 
other establishments usually developed occupational lung disease after a period of time at work. Occurrence of symptoms immediately after exposure to a dust was exceptional, the only other instance being mill fever, which consisted of influenza-like symptoms that lasted during the first day or two of exposure to cotton, flax, hemp and kapok dusts.

I was disheartened by the remarks of two well known Professors from each of the Faculties of Medicine at Peradeniya and Colombo who were critical of the purpose of doing research on chilli grinders. Nevertheless, the acceptance of my paper in toto by the British Journal of Industrial Medicine in 1967 encouraged me to delve into other fields of occupational lung disease. I found that the effects of dusts, such as those of tea, kapok, coir, ilmenite, coconut-shell charcoal, cinnamon and other spices had not been investigated, and I took them up in turn.

I may mention that if not for my experience of developing cough and sneezing on entering the chill grinding mill, I doubt my taking up this line of work. My going to the grinding mill to purchase chilli powder was the catalyst that set in motion the study of occupational lung disease. The assistance given by the late Dr Perera stood me in good stead in later work when I had to get workers in some of the other industries to come to the chest clinic for examination.

World Health Organization decided in 1983 to publish a document on diseases caused by dusts of vegetable origin. Two meetings to draft this document were held, one in Alexandria in Egypt and the other in Morgan Town in the USA. Those present at the meetings classified these diseases into occupational asthma, extrinsic allergic alveolitis, chronic obstructive pulmonary disease and byssinosis. All these conditions developed after a period of work in the occupation, usually counted in terms of years rather than weeks or months. Chilli grinder's disease, which comes immediately on starting the occupation, does not fall into any of these categories. It deserves a separate place in the classification. Though I was present at these meetings, I did not raise the question of this omission, as my findings had not been confirmed by any one else up to that time.

Professor R. Rylander of Sweden subsequently formulated a new classification, the main change being the inclusion of mill or toxin fever. Toxin fever, according to Rylander, is caused by an exotoxin found in some vegetable dusts. Symptoms in chilli grinders are caused by a different mechanism, namely the action of capsaicin, the active principle of chilli.

It was only in 1990 that workers in Singapore confirmed that symptoms in chilli grinders date from the beginning of their employment and wane with time. Since my findings were now substantiated, I made the plea in an invited address at the Third Asia Pacific Society of Respirology held in Singapore in 1993, that chilli grinder's disease should be included as a separate entity in the classification of diseases caused by vegetable dusts.

Capsaicin, the active principle of chilli, has now become a subject of intense research throughout the world. The nervous pathway in the lung, along which stimuli from capsaicin travelled, was found to be different from all the other pathways. Even morphine would not suppress the cough reflex induced by capsaicin. Hence research on capsaicin is likely to be the basis for the development of new cough suppressants. Chilli, which was unsung when I first worked on it 1967, has now assumed much importance. 